\title{
Temporal changes in the potential geographic distribution of Histiotus velatus (Chiroptera, Vespertilionidae), the "decade effect"
}

\author{
Liriann Chrisley Da Silva ${ }^{1}$, Rafaela Almeida ${ }^{2}$, Pablo Silva ${ }^{3}$, Monik Oprea ${ }^{2}$, Poliana \\ Mendes $^{4}$, Daniel Brito ${ }^{2}$, and Thiago Bernardi Vieira ${ }^{1}$ \\ ${ }^{1}$ Universidade Federal do Pará - Campus Altamira \\ ${ }^{2}$ Universidade Federal de Goiás \\ ${ }^{3}$ Universidade Estadual de Goiás \\ ${ }^{4}$ Université Laval Faculté des sciences de l'agriculture et de l'alimentation
}

May 27, 2021

\begin{abstract}
Also investigate how the potential distribution of this species changes with the addition of new records over the decades (decade effect). Assuming that (1: hypothesis of the effect of the decade) the addition of new occurrence records over time increases the potential size of the species distribution; and (2: Wallacean distance hypothesis) over the years, the new points added are increasingly distant from the research centers. Considering the geographic knowledge gap of Histiotu velatus, our objective is to report a new record of this species and estimate its potential distribution in South America through ENMs. For this, we compiled records of occurrence of species, selected from 1900 to 2015 . We used 19 bioclimatic variables available in the WorldCLim database to estimate the potential distribution of the species and we used three modeling algorithms: Maximum Entropy (MXT) Random Forest (RDF) and Support Vector Machine (SVM). We selected the main bat research centers in Brazil, using the Lattes platform for the Wallacean distance hypothesis, using the Euclidean distance calculation. To test the hypothesis of the decade effect, we used beta regression analysis, taking conservative and non-conservative approaches. The results showed that the predicted area expanded and retracted over the decades, with an improvement in the accuracy of the models with the addition of new data. Most of the records are located in the southeastern region of Brazil, but the algorithms predicted areas in countries where there were no records. Only the conservatism approach has had a positive relationship over the decades. The distance from new points does not increase over the years of research centers.
\end{abstract}

\section{Hosted file}

DaSilva16052021.doc available at https://authorea.com/users/300959/articles/523776-temporalchanges-in-the-potential-geographic-distribution-of-histiotus-velatus-chiropteravespertilionidae-the-decade-effect 

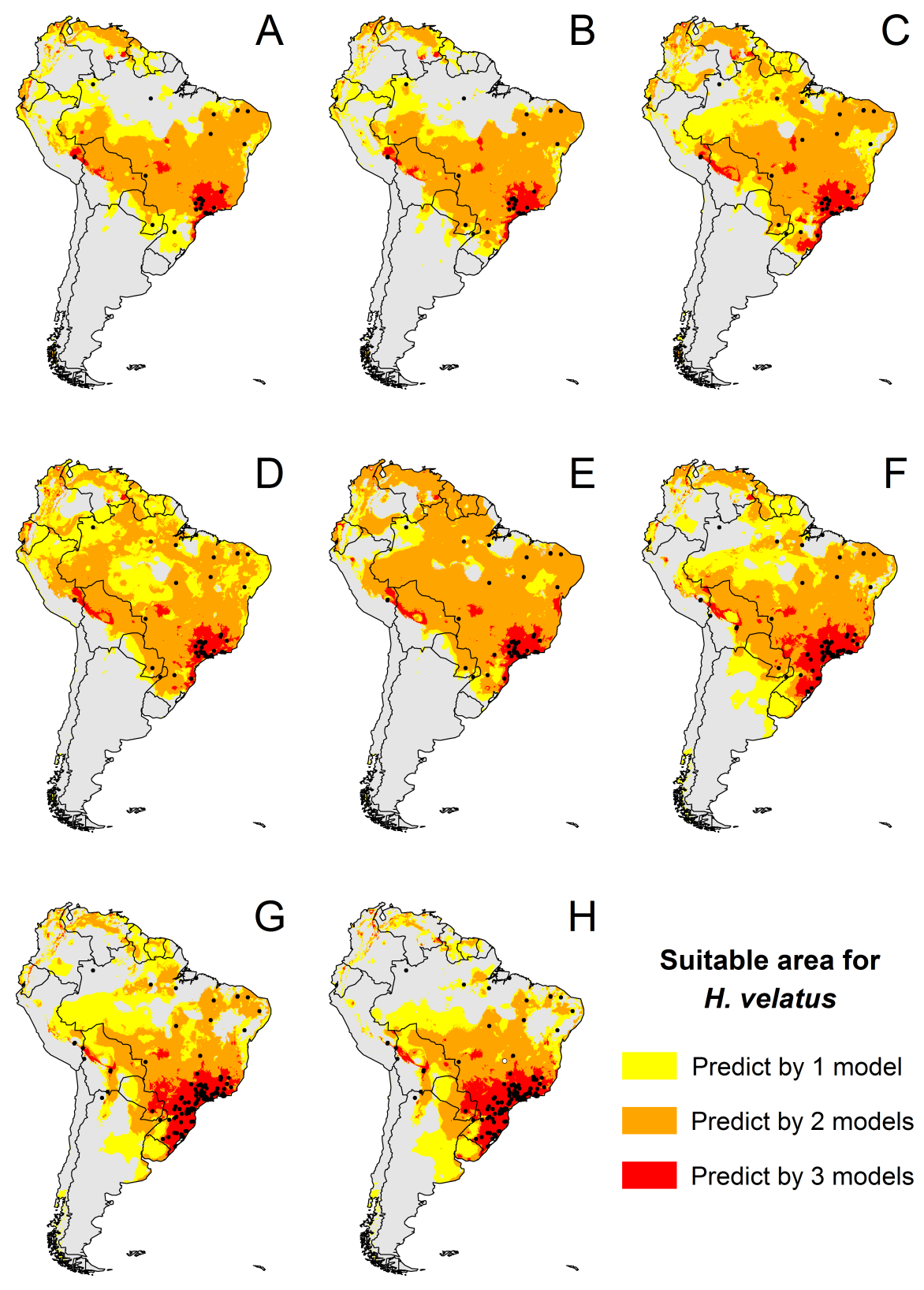

\section{Suitable area for $H$. velatus}

Predict by 1 model

Predict by 2 models

Predict by 3 models 

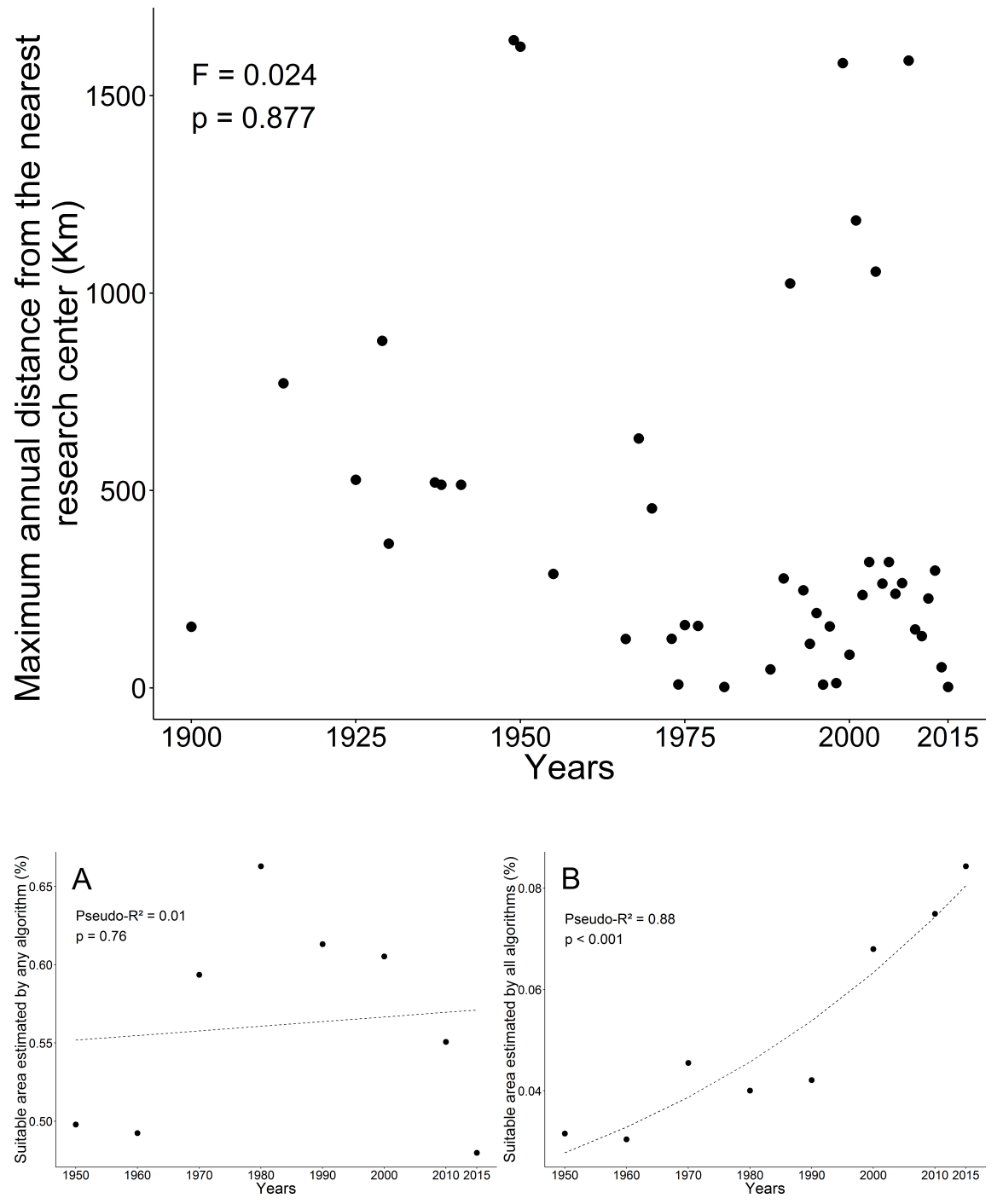

3 